This item was submitted to Loughborough's Research Repository by the author.

Items in Figshare are protected by copyright, with all rights reserved, unless otherwise indicated.

\title{
A reflection on the first 50 years of Water Resources Research
}

PLEASE CITE THE PUBLISHED VERSION

http://dx.doi.org/10.1002/2015WR018089

\section{PUBLISHER}

(c) American Geophysical Union

VERSION

VoR (Version of Record)

\section{PUBLISHER STATEMENT}

This work is made available according to the conditions of the Creative Commons Attribution-NonCommercialNoDerivatives 4.0 International (CC BY-NC-ND 4.0) licence. Full details of this licence are available at: https://creativecommons.org/licenses/by-nc-nd/4.0/

\section{LICENCE}

CC BY-NC-ND 4.0

\section{REPOSITORY RECORD}

Rajaram, Harihar, Jean M. Bahr, Gunter Bloeschl, Ximing Cai, D. Scott Mackay, Anna M. Michalak, Alberto Montanari, Xavier Sanchez-Villa, and Graham C. Sander. 2019. "A Reflection on the First 50 Years of Water Resources Research”. figshare. https://hdl.handle.net/2134/19843. 


\section{Water Resources Research}

\section{REVIEW ARTICLE}

10.1002/2015WR018089

Special Section:

The 50th Anniversary of Water Resources Research

\section{Key Points:}

- History of Water Resources Research

- Research trends in hydrology over

the last 50 years

- Some bibliometrics of Water

Resources Research

Supporting Information:

- Supporting Information S1

Correspondence to:

H. Rajaram,

hari@colorado.edu

Citation:

Rajaram, H., J. M. Bahr, G. Blöschl,

X. Cai, D. Scott Mackay, A. M. Michalak,

A. Montanari, X. Sanchez-Villa, and

G. Sander (2015), A reflection on the

first 50 years of Water Resources

Research, Water Resour. Res., 51, 7829-

7837, doi:10.1002/2015WR018089.

Received 9 SEP 2015

Accepted 23 SEP 2015

Accepted article online 29 SEP 2015

Published online 19 OCT 2015

\section{A reflection on the first 50 years of Water Resources Research}

\author{
Harihar Rajaram ${ }^{1}$, Jean M. Bahr², Günter Blöschl3 ${ }^{3}$ Ximing Cai ${ }^{4}$, D. Scott Mackay5, Anna M. Michalak ${ }^{6}$ \\ Alberto Montanari7, Xavier Sanchez-Villa ${ }^{8}$, and Graham Sander9 \\ ${ }^{1}$ Department of Civil, Environmental, and Architectural Engineering, University of Colorado, Boulder, Colorado, USA, \\ ${ }^{2}$ Department of Geoscience, University of Wisconsin-Madison, Madison, Wisconsin, USA, ${ }^{3}$ Institute for Hydraulic and \\ Water Resources Engineering, Vienna University of Technology, Vienna, Austria, ${ }^{4}$ Ven Te Chow Hydrosystems Laboratory, \\ Department of Civil and Environmental Engineering, University of Illinois at Urbana-Champaign, Urbana, Illinois, USA, \\ ${ }^{5}$ Department of Geography, State University of New York at Buffalo, Buffalo, New York, USA, ${ }^{6}$ Department of Global \\ Ecology, Carnegie Institution for Science, Stanford, California, USA, ${ }^{7}$ Department of Civil, Chemical, Environmental, and \\ Materials Engineering, University of Bologna, Bologna, Italy, ${ }^{8}$ Department of Geotechnical Engineering and Geosciences, \\ Hydrogeology Group, Universitat Politecnica de Catalunya Barcelona Tech, Barcelona, Spain, ${ }^{9}$ Department of Civil and \\ Building Engineering, Loughborough University, Loughborough, UK
}

Abstract The year 2015 marks the 50th anniversary of Water Resources Research (WRR), which was founded in 1965. More than 15,000 papers have been published in WRR since its inception, and these papers have been cited more than 430,000 times. The history of hydrology and the water sciences are also reflected in WRR, which has served as a premier publication outlet and instigator of scientific growth over the last 50 years. The legacy of WRR provides a strong scientific foundation for the hydrology community to rise to the challenges of sustainable water resources management in a future where dramatic environmental change and increasing human population are expected to stress the world's water resources from local to global scales.

\section{Introduction}

On this occasion of the 50th anniversary of Water Resources Research (WRR), as members of the current editorial team, we present some reflections on the history of the journal and its contributions to hydrology and water science. We perused the collection of articles and editorials published in WRR over the last 50 years, consulted the American Geophysical Union (AGU) newsletter EOS to better understand the context for the establishment of WRR; and examined various bibliometric indices. We also reached out to several former editors of WRR for their recollections. WRR was fortunate to be served by 29 dedicated editors in previous editorial teams. We found that their editorials provided an accurate window into the challenges and trends in research during various periods, and we have drawn from them to trace the history of the journal.

As an additional approach to tracing the evolution of research trends in WRR, we considered the most highly cited papers in each decade in the first 50 years. Our analysis was based on the web of science. Table 1 summarizes the topics covered by the 10 most highly cited papers of each decade and is referred to at several points below. The titles of the 10 most highly cited papers from each decade and their citation statistics are included as supporting information. Additionally, we examined the 50 most highly cited papers in each decade for a larger sample of prominent papers. Figure 1 shows word clouds (which give greater prominence to words that appear more frequently) generated by wordle (www.wordle.net) from the titles of these papers. We acknowledge that citations alone do not provide a complete picture of research activity or impact. Nevertheless they provide a useful window into the evolution of the discipline as reflected in WRR.

\section{A Brief History of WRR}

At the time when WRR was established, there were only two other scientific journals devoted to hydrology-the Hydrological Sciences Journal (established in 1956) and the Journal of Hydrology (established in 1963). The first issue of WRR was published in March 1965, with Walter Langbein and Allen Kneese as (c) 2015. American Geophysical Union. All Rights Reserved. 
Table 1. Topics Covered by the 10 Most Highly Cited Papers in Water Resources Research in Each Decade Since Its Inception Decade $\quad$ Topics Covered by the Top 10 Most Highly Cited Papers of the Decade

1965-1974 Evapotranspiration, runoff generation mechanisms, stochastic hydrology/hydrologic time series (especially in the context of streamflow), fractional stochastic processes, infiltration, analytical solutions to subsurface flow and transport.

1975-1984 Subsurface transport processes, unsaturated hydraulic conductivity functions, macropores, soil moisture measurement; atmospheric radiation and surface energy balance; stochastic subsurface hydrology and macrodispersion; statistical hydrology and stochastic simulation.

1985-1994 Rainfall-runoff models (lumped and distributed), unsaturated flow modeling and soil properties, field-scale transport in groundwater and natural-gradient tracer tests, inverse problems in groundwater, acid deposition and streamwater chemistry, reservoir management, lansdslides.

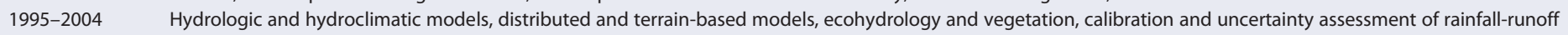
models, landslides, turbulence-vegetation interactions, arsenic in groundwater.

2005-2014 Uncertainties in hydrologic modeling, Bayesian data assimilation, climate change impacts, and geological $\mathrm{CO}_{2}$ storage.

co-editors. The minutes of the American Geophysical Union council meeting in December 1964, as reported in the Transactions of the American Geophysical Union from March 1965, state: "It was reported that steps were being taken to implement the approved plan to establish a new quarterly entitled Water Resources Research. Many fliers have been sent to members and to prospective subscribers. Prior to Christmas, 1680 orders for the new journal had been received."

Under "special announcements" in the same issue of the transactions, the launching of the WRR is highlighted: "The journal also covers the activities of the International Hydrological Decade. Papers in the physical, chemical, or biological sciences should be sent to Walter B. Langbein, U. S. Geological Survey, Washington, D.C. 20241. Papers on the social sciences, including economies and law, should be sent to Allen V. Kneese, Resources for the Future, 1755 Massachusetts Avenue, N. W., Washington, D.C. 20036."As reflected in the call for papers, the early editorial teams for WRR (1965-1985) typically involved two editors: one handling papers on physical, chemical, and biological sciences; and the other handling social sciences. Results of research from major initiatives on water resources systems analysis, such as the International Hydrological Decade (1965-1975) and the Harvard Water Program (initiated in 1955), were published in WRR. Walter Langbein played an instrumental role in steering the International Hydrological Decade, which laid the foundations for standardizing water-related data collection and long-term studies of experimental basins internationally. His contributions as founding editor of WRR from 1965to 1969 are recognized in a tribute from Helmut Landsberg (then president of AGU) in the first issue of 1970.

George H. Davis, editor of WRR for the physical sciences from 1970 to 1976 elaborates further on the background for the establishment of WRR in his 25th anniversary reflection [Davis, 1990]. He notes that Langbein and Kneese needed to "beat the bushes" and vigorously solicit papers for the first issue. The very first paper in the first issue of WRR was authored by Kenneth J. Arrow, on criteria for social investments, which is related to the welfare theory for which he won the Nobel Prize in economics seven years later. The broad multidisciplinary focus of WRR was already evident in the topics addressed by papers published in the 1960s-economics, social issues, public policy, water resources law and regulations; many aspects of surface and groundwater hydrology; stream, lake and groundwater quality; pollution and contaminant transport; hydrogeochemistry; geomorphology and sediment transport; atmospheric radiation and evaporation; snow and snowmelt. The journal was already living up to the vision behind its establishment, as stated in the inside cover of the early issues:

The development of water resources is linked to many sciences. The Section of Hydrology of the American Geophysical Union has long considered that its role as a forum for research in the sciences of water transcended "hydrology" and included other natural sciences such as fluid mechanics, geochemistry, and geomorphology. This readiness to serve is now enlarged to include the sciences that pertain to the practical reason for water research in all fields. These are the social sciences that provide sound principles as guides to the public decisions about the development of water.

As evident from the mission of the journal stated above, WRR was inspired by a specific desire to integrate the social and natural sciences in the context of water resources development. Charles W. Howe (editor of WRR for economics and social sciences, 1968-1975) in a personal communication remarked: "It took some urging to get the social science people to publish in WRR since their traditional outlets were elsewhere. Nonetheless, WRR can proudly exhibit path-breaking articles in the social science areas, including 


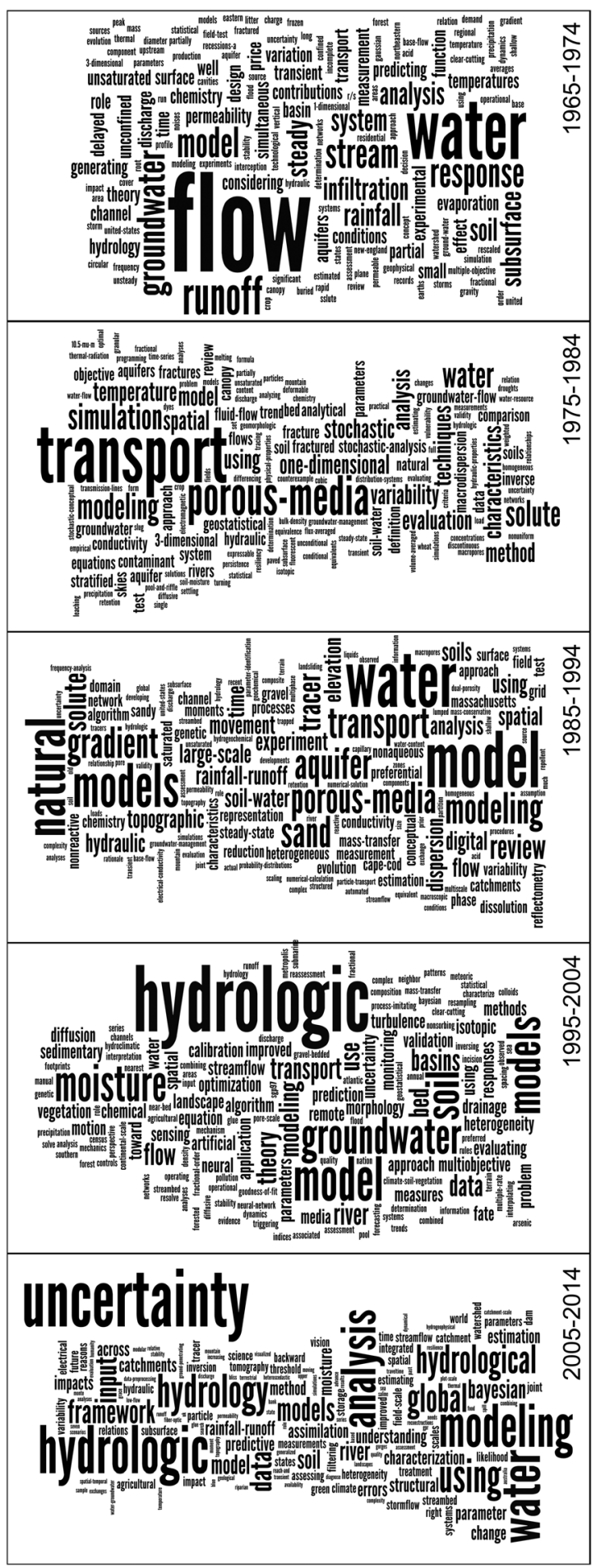

Figure 1. Word clouds based on the titles of the 50 most highly cited papers from each decade of Water Resources Research. The clouds give greater prominence to words that appear more frequently in the titles, providing a visual representation of the themes emphasized in each decade. historically key contributions in the study of water demand, the economics of water quality management and flood control." Since the early days, environmental and natural resource economists have published papers in WRR, especially on water resources development and management.

In addition to the various subfields noted above, WRR was also becoming a forum for dissemination of a wide range of innovative mathematical approaches for modeling and analysis of hydrologic and water resources systems-analytical and numerical methods for partial differential equations, systems theory, stochastic and statistical methods, and optimization. In fact the first special section in WRR was a collection of papers from a Symposium on Analytical Methods in Hydrology in 1967, which contained overview papers on optimization, time series analysis, spectral analysis, nonlinear systems analysis, linear hydrograph theory, finite-difference methods, and electrical analogs for groundwater modeling. A good balance of papers on engineering applications and scientific aspects was also evident in the first 5 years. By the end of the 1970s, WRR had developed a strong reputation as an outlet for fundamental scientific inquiry into hydrologic processes and the deeper mathematical underpinnings of modeling approaches. Freeze [1981] notes that by this time, WRR was widely perceived as the leading journal in the field. At the same time, he notes the perception that WRR was a "theoretical journal" that favored theoretical papers at the expense of applied papers. He emphasized that although routine applications/case studies were unlikely to be accepted, WRR was always interested in seeing more papers that reported careful field measurements leading to original or creative hydrologic insights. This is a standard that continues to be exercised in the WRR review process to this day.

In the first decade (1965-1974), the topics that stand out from Table 1 reflect advances in fundamental understanding of various components of the hydrologic cycle-streamflow and runoff generation in particular, evaporation, and infiltration. It is noteworthy that many of these papers indeed developed mathematical models and novel insights into hydrologic processes based on field measurements, as noted by Freeze [1981]. Additional areas of focus were stochastic hydrology and the properties of hydrologic time series, and analytical solutions to groundwater flow and transport problems, including well hydraulics. In our view, many significant theoretical developments from this period 
are indeed incorporated into the practice of surface and subsurface hydrology today. Concepts considered "theoretical" at one stage in the development of a field, sometimes transition into "practical" tools at a later stage.

For the second decade (1975-1984), the topics in Table 1 reflect the growing emphasis on subsurface transport processes and porous media, especially on unsaturated flow and soil property measurements. There was also a tremendous growth of stochastic modeling concepts, both in surface and subsurface hydrology, encompassing physical-stochastic models, stochastic continuum approaches, and synthetic generation of hydrologic time series and random fields. Other topics that figure prominently in the 50 most highly cited papers are atmospheric radiation and surface energy balance, hydrochemistry, stochastic simulation, and fundamental studies of hydrologic response.

In editorials at the end of the second decade, Cohon [1984] and Burges [1984] again reflect on the perception that WRR was a "mathematical" or "theoretical" journal. Cohon [1984] writes: "A perennial problem is theory versus practice. Is WRR too theoretical? Does it really serve the needs of the readership? Is it read at all by practitioners? .... Someone has suggested that a new, additional water journal, focusing on applications, be published by AGU." In reflections from former editors of WRR on the occasion of the 25th anniversary, Burges [1990] comments further on the dichotomy of "scientific" and "engineering" approaches to research: "Engineers tend to wait and write as completely about a particular problem as is possible because they have needed to develop and implement a solution to that problem. The pure scientist is less problem driven and can explore a major field of inquiry in varying levels of detail." He emphasizes the importance of WRR as an outlet for both types of work. Indeed, practical engineering applications/needs have inspired fundamental scientific inquiry in hydrology and the water sciences, and have in turn benefitted from such inquiry. Freeze [1990] offers the reconciliation of "process-oriented" and "prediction-oriented" schools of streamflow forecasting, the hydrologic cycle, and surface water research, as an example of the positive impact of interactions between theory and practice that WRR facilitated. The synergy between science and engineering is also apparent in the large body of papers in WRR devoted to groundwater contamination and remediation, which encompass small-scale chemical and microbial processes controlling contaminant transformations, field-scale computational models, and numerous controlled and natural field-scale tracer tests, all of which have contributed to the science and engineering behind remediation efforts such as Superfund in the U.S.A. and related efforts in other countries.

From the late 1980s into the mid-1990s, there was a push to establish hydrology as a distinct Earth science, or alternatively to strengthen its status as an Earth science, in parallel with efforts at the National Research Council of the United States. [National Research Council, 1991] and other initiatives aimed at strengthening hydrological educational programs [e.g., Nash et al., 1990]. A special issue of WRR titled, "Trends and Directions in Hydrology," edited by Burges [1986], was published in 1986. In the editorial to that volume, Burges [1986] suggests the need for a greater coherence to the study of hydrology. Hornberger [1993], who served as editor of WRR from 1993 to 1996, also emphasized the need to overcome fragmentation as a prerequisite for hydrology to develop as a distinct and unified science. Beginning in this period, significant developments in technology led to a vast expansion in the range of observations that hydrologists could utilize to improve understanding of hydrologic processes (e.g., advanced weather radar systems, remote sensing, digital terrain models, multi-level samplers, shallow subsurface geophysics). It is noteworthy that many of the early papers that incorporated these technological developments in hydrologic research were reported in WRR.

Two other classes of developments occurred at the same time, providing a boost to the enterprise of hydrologic science. First, vastly enhanced computational capabilities made it possible to bridge long-standing scale gaps in surface and subsurface hydrology: high-resolution distributed simulations of large watersheds could be performed by combining digital terrain models and smaller-scale hydrologic models; pore-scale processes could be upscaled to the continuum scale; and subsurface flow and transport models could employ submeter-scale grids for simulating behavior at $100 \mathrm{~m}-1 \mathrm{~km}$ field scales. Second, theoretical paradigms for understanding the behavior of complex and heterogeneous systems evolved in many disciplines. WRR, by virtue of its reputation as a "theoretical" journal, led the charge in promoting novel theoretical approaches in hydrology and the adaptation of approaches developed in other fields. Indeed, one could argue that researchers pursuing novel theoretical approaches to hydrologic problems could always count on WRR as a forum for disseminating their ideas. Advances in hydrologic applications of stochastic theories 
and stochastic processes, geostatistical methods, Bayesian formalisms for inference and assimilation, stochastic optimization, scaling laws and nonlinear dynamics, all reported in WRR papers of this era, bear witness to the expansion of rich analytical tools available to hydrologic science. As noted previously, a substantial body of research on stochastic models is evident in WRR since the early days. In the period 1988-1992, WRR in fact specifically designated an editor to handle papers on stochastic hydrology and related areas (Soroosh Sorooshian), while a different editor (Roger Smith) handled papers on physical studies of hydrologic processes.

The third decade 1985-1994 emphasized hydrological modeling. Large-scale natural gradient tracer tests in groundwater, modeling field-scale dispersion processes, and rainfall-runoff modeling were prominent topics (Table 1). The breadth of topics covered for 1985-1994 in Table 1 is quite impressive, including acid deposition and hydrochemical response of watersheds, reservoir management, and landslides. A more detailed examination of the 50 most highly cited papers reveals a vast expansion of modeling capabilities in unsaturated zone hydrology, rainfall runoff processes, and reactive contaminant transport. This period also witnessed the integration of mature stochastic streamflow models and stochastic optimization theory to greatly advance the framework for reservoir operations and water resources management, in what may be viewed as a culmination of the original vision behind the Harvard Water Program.

In the later half of the 1990s, efforts to strengthen hydrologic science intensified further. The challenges in maintaining the interdisciplinary flavor of WRR during this time of rapid development and emergence of other journals in hydrology are summarized in an editorial by Gray and Bencala [2003]. In Table 1, summarizing the topics of the 10 most highly cited papers for this period, we find the emergence of hydroclimatic models, ecohydrology and vegetation, turbulence-vegetation interactions, and interest in global water crises such as arsenic in groundwater. Additionally, research at the interface between hydrology and geomorphology expanded significantly, while traditional areas such as groundwater continued to receive attention. Closer examination of the detailed titles of the 50 most highly cited papers suggests an emerging focus on hydrologic processes and models at scales beyond the "traditional" watershed scale, to regional and continental scales, and the relevance of soil moisture measurements and dynamics in this context. Analyses of regional and continental hydrologic data sets also expanded significantly during this period. These developments and their influence on hydrology and WRR are recognized in an editorial by Parlange et al. [2005]: "We envision WRR continuing as a leader in defining processes that enable upscaling to regional and continental scales and downscaling to subgrid-scale processes such that the full dynamics of eco-chemo-hydrological systems can be appreciated and quantified." The emphasis on an integrated hydrologic science comes across clearly in this vision. It would be fair to say that the hydrology community was making progress towards achieving a sense of coherence and overcoming the fragmentation alluded to by Hornberger [1993]. However, there is room for further progress to this day. Continued efforts must be pursued to build a coherent science by more tightly relating different studies and making published research outcomes generalizable, as noted in the more recent editorial of Blöschl et al. [2014]. Hydrologic processes set up a template for a host of other processes influenced by water-including geomorphology, aqueous geochemistry, and ecology. One could add that advances in all these fields benefitted indirectly from developments in hydrology; this is very much in evidence from the broad interdisciplinary flavor that comes across in WRR during the 1990s and 2000s, and the fact that researchers from other disciplines regarded WRR as an attractive publication outlet.

The coupling of atmospheric, ecological, and hydrologic models in the context of global environmental change led to significant interactions between hydrologists and other geoscientists, with mutual benefits. Efforts to predict global environmental change have benefitted from the incorporation of hydrologic feedbacks in land-atmosphere coupled models. As a result, new opportunities for research in hydrologic science emerged, while also expanding the scope of hydrologic practice. The influence of climate change and lowfrequency climate variability indices such as El Niño on regional streamflows, drought indices, snowpack, and snow hydrology, were also recognized as a result of greater communication across disciplines, and have contributed significantly to hydrologic forecasting in the context of water management. This is yet another example of the synergy between theory and practice alluded to by Freeze [1990].

For the period 2005-2014, Table 1 reflects an emphasis on uncertainty assessment. A detailed examination of the 50 most highly cited papers reveals developments in Bayesian data assimilation techniques applied to hydrologic models across a range of scales. A new paradigm of global hydrology began to expand greatly during this period, and several prominent papers addressing global water issues appeared in WRR. 
At the same time, the emphasis on ecohydrology and soil moisture continued, while the fields of hydrogeophysics and subsurface carbon sequestration expanded significantly.

For a period of 16 years (1993-2008) that marked the emphasis on hydrologic science, the editors of WRR were selected exclusively from the natural sciences. This is not to say that the social science and policy issues were no longer of interest to WRR. In fact, a deputy editor was explicitly assigned to this area between 1993 and 2004. Yet, there was a decline in submissions in these areas during the 1990s, and editorial teams made efforts to address this. Despite this trend, it is interesting that notable economists continued to publish papers in WRR during this period (including Elinor Ostrom, the only woman to win the Nobel Prize in economics to date). Four special sections were devoted to economics and policy in 2004 (the most recent previous special sections on these themes had been published in 1993). In the later half of the 2000s, the broad themes of water and resource sustainability under climate change came to the fore. The term "anthropocene" had already been coined in 2000 to recognize the impact of humans on Earth's ecosystems. The emergence of global water sustainability and water security as important themes are all closely related to the notion of change, of considering the long-term dynamics of the water cycle, and of including pervasive human influence during the anthropocene, which is inherently shaped by social and economic factors. Quite appropriately, the editorial teams of WRR since 2008 have again included an editor representing the social sciences, economics, and policy. A search in web of science indeed reveals a sharp increase in the number of papers published in these fields (not just in WRR, but in all journals), in the later half of the 2000s.

In their editorial, Kumar et al. [2009] highlight the changes in the hydrologic cycle at several scales in relation to climate change. They present a renewed charge to the hydrology community: "The interaction of the water cycle and its components across interfaces, disciplines, and scales continues to pose challenges. We welcome articles addressing this coupling and complexity of the hydrologic cycle, the mass and energy transport it facilitates, and the interactions of both natural and anthropogenic processes." It is interesting that this renewed interest in social sciences and water science for society (one of the themes of this special issue) is reminiscent of the early years of WRR. WRR may be going back to its roots. The close link of WRR with early international initiatives such as the International Hydrological Decade and Harvard Water Program of the 1960s and 1970s, parallels the link between the water science for society theme and current international initiatives such as the Panta Rhei scientific decade promoted by the International Association of Hydrological Sciences [Montanari et al., 2013].

Much of the early work on human-water interactions revolved around the impact of water on people (including many economic studies); later research centered around the impact of people on water (including contamination and environmental impact studies); the more recent thrust on sociohydrology may be a reflection of the greater recognition of the importance of feedbacks between people and water, which occur across a range of spatial and temporal scales. The interdisciplinary view that WRR has so effectively fostered over the last 50 years will then be moved forward to a new coevolutionary view that accounts for the rapid and widespread changes brought about by humans, where the human influence is considered an integral part of the hydrologic cycle. In approaching these renewed challenges, the 50 year legacy of WRR-the rich body of papers collectively representing tremendous developments in theoretical and computational tools, modern observational and remote sensing technologies, undoubtedly provides a valuable foundation for future research.

\section{Vignettes on the Financial Aspects of WRR}

The financial backdrop for WRR's establishment is discussed in the appendices of the March 1965 issue of the Transactions of the American Geophysical Union-funds were being borrowed from the general reserve of AGU under security of the Horton will, and the council was attempting to secure a grant of $\$ 25,000$ to aid in the establishment of the journal. The subscription rates were set at $\$ 3.00$ per calendar year for AGU members and $\$ 6.00$ for nonmembers. The expectation was that WRR would be financially self-sufficient within a few years.

The success of WRR as a leading outlet for papers in the water sciences was already evident in the growth from a quarterly to a bimonthly publication, starting in 1968 (WRR transitioned to a monthly publication much later, in 1984). By this time, hydrology had already become the largest division within AGU. Davis 


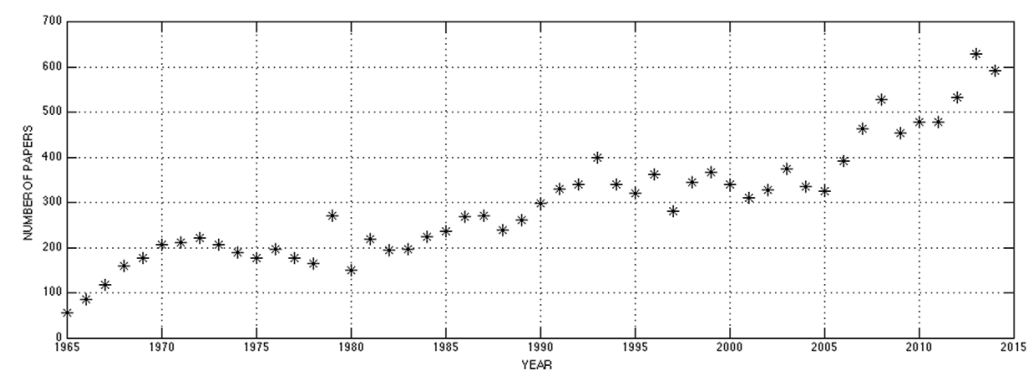

Figure 2. Papers published in Water Resources Research each year since its inception in 1965.

[1990] notes that the growth of WRR during this period posed a bit of a challenge for financial reasons. Despite significant growth, the journal was incurring losses, to some extent because of the large number of papers on which page charges were not paid. An unusual practice of deferring publications at the end of the year (which led to "thin" December and "fat" February issues) was sometimes resorted to, in an attempt to balance budgets. Davis [1990] further notes: "To AGU's everlasting credit, however, AGU never rejected or deferred papers on the basis of whether or not page charges were honored. In my experience, the only criterion for publication was technical merit." Freeze [1981] also recalls a misconception among many authors that they would not be able to publish their papers in WRR because of an inability to pay page charges. In this context, the hydrology community owes a debt to AGU for its sustained support of WRR through difficult financial periods. To this day, WRR continues to offer reasonable subscription rates $(\$ 138$ per year online subscription for individuals), thus maintaining its tradition as an accessible publication outlet. Publication costs in WRR today are free of charge up to 25 publication units, with a cost of $\$ 125$ per publication unit thereafter (a publication unit refers to 500 words of text or a figure or table). In step with technological developments that impacted research, the review process in WRR began to transition to electronic submission and review in 2001. Today WRR is mostly an electronic publication, although a few individual paper subscriptions continue to be honored. WRR is now accessible to researchers worldwide, and the current policy enables free electronic access to papers between 1997 and 24 months prior to the access date.

In 2012, the Board of Directors of AGU decided to outsource the production, sales, distribution, and subscription of AGU journals to Wiley-Blackwell starting from January 2013; while retaining ownership and control of the scientific aspects of publications, including editorial control and oversight by AGU governance. This decision was motivated by a need to stay up-to-date in a rapidly evolving publishing marketplace, by adopting a business model for journal production that is widely used by scientific associations. Specifically, with this publication model, the volunteer leadership and staff resources can be focused exclusively on advancing scientific content, improving quality, and sustaining editorial excellence, rather than on the operational functions of publishing. Although this may be viewed as a very significant change, the accessibility of WRR for authors, the efficiency of the review and publication process, and the scientific reputation of the journal are largely unaffected by it.

\section{Some Bibliometrics}

The number of papers published in WRR in each year since 1965 is shown in Figure 2. After a period of rapid growth between 1965 and 1972, there was a slight decline until 1980 ( 200 papers/year in 1979-1980). Subsequently, there was another period of rapid growth until 1995 ( 340 papers/year in 1994-1995), followed by a leveling off until 2005. After 2005, the number of papers has increased substantially in this era of digital and electronic publication. The number of papers published in 2013 and 2014 were 628 and 591, respectively. Overall, more than 15,000 papers have been published in WRR since its inception. As WRR has grown, the magnitude of the number of papers that requires handling has also increased. For instance, there were 1461 submissions in 2013. Correspondingly, the number of associate editors (AEs) also grew from about 25 in 1980 (at its inception in 1965, there were 12), to 40 in 1990 (the 25th year) to about 100 today. On average, AEs handled about 15 manuscripts per year in 2013. Between 1993 and 2004, the 

Decade as of 1 September $2015^{a}$

\begin{tabular}{lccccc} 
Period & $\begin{array}{c}\text { Number of } \\
\text { Papers } \\
\text { Published }\end{array}$ & $\begin{array}{c}\text { Total } \\
\text { Citations }\end{array}$ & $\begin{array}{c}\text { Average } \\
\text { Citations } \\
\text { per Paper }\end{array}$ & h-Index & $\begin{array}{c}\text { Citations } \\
\text { During } \\
\text { 2012-2014 }\end{array}$ \\
\hline $1965-1974$ & 1,629 & 40,277 & 25 & 93 & 1,164 \\
$1975-84$ & 1,976 & 80,342 & 41 & 126 & 3,070 \\
$1985-94$ & 2,981 & 140,716 & 47 & 159 & 5,776 \\
$1995-2004$ & 3,365 & 127,257 & 38 & 131 & 9,191 \\
$2005-2014$ & 4,873 & 58,488 & 15 & 79 & 12,590
\end{tabular}

${ }^{\mathrm{a}}$ The number of papers published in each period varied significantly (see Figure 1). Note that older papers have received citations over a longer period than more recent papers.
Table 2. Citation Statistics for Water Resources Research Papers from Each

composition of the editorial board was changed from the original model of two editors with one focused on physical, chemical, and biological sciences, and another on social sciences, economics, and policy. From 1993 to 2000, there was a single editor, followed by two editors (2001-2004), with several deputy editors (DEs) handling different disciplines between 1993 and 2004. During this period, almost all volumes of WRR appeared with separate sections-subsurface hydrology; surface water and climate; hydrogeochemistry and water chemistry; water policy, and economics; and erosion, sedimentation, and geomorphology. However, it should be emphasized that this division of papers was not intended to separate the sub-disciplines. It was motivated by a request from the geomorphology community to provide them with a clearly identified home within the AGU family of publications. Deputy editors were initially assigned to each of the sections mentioned above, but subsequently, the number of DEs ranged from 4 to 10, and the disciplines covered by the DEs also varied in response to submission trends. Due to the significant growth of WRR, the number of editors was increased to five in 2005 , eliminating DEs, and grew to eight in 2013. Starting in 2005 (coincidentally Journal of Geophysical Research-Earth Surface Processes, incorporating geomorphology, was initiated in 2003), the separation into disciplinary sections was discontinued, to encourage broad submissions and interdisciplinarity that transcended such separation.

In terms of citations, papers published in WRR have been cited over 430,000 times as of 1 September 2015. A total of 31 papers have been cited more than 500 times; most of these papers are reflected in the topics listed in Table 1. The number of papers cited more than 400, 300, 200, and 100 times, respectively exceed $50,100,270$, and 900 . Table 2 shows the total number of citations of WRR papers published in each decade, along with the corresponding cumulative average citations per paper, h-index, and average number of citations during the years 2012-2014. The highest cumulative citations are associated with the papers from 1985 to 1994, with an average of 47 citations per paper and an h-index of 159. The lower citations of the papers from 1995 to 2004 and 2005 to 2014 are in large part due to the time it takes to build up citations. The citations of these papers in 2012-2014 are significantly higher than those of the 1985-1994 papers, and the average citations per paper from 1995 to 2004 may well exceed 50 by the end of this decade. These metrics are clearly indicative of an active and vibrant journal. It is noteworthy that the impact factors of WRR in 2013 and 2014 were 3.709 and 3.549, respectively, which are the highest among journals in hydrology.

\section{Concluding Remarks}

During its first 50 years, WRR has witnessed the growth of the discipline of hydrology not just as a publication outlet, but as an instigator of scientific growth by defining new cutting-edge research, contributing to the solution of important open problems, and acting as a catalyst for interdisciplinary research by producing collections of papers and special volumes. The history of WRR is intertwined with the history of hydrology and provides a unique perspective on the evolution of the field and the increasing human pressure on water resources. WRR clearly exemplifies the vital role that journals and scientific publishing play for science, to catalyze scientific discovery and futuristic ideas.

The legacy of WRR provides everlasting inspiration and sets the stage for the hydrology community to rise to the monumental challenges of sustainable water supply and security in a period of dramatic environmental change and increasing human population. Challenges related to the water-food-energy nexus, carbon capture and sequestration, and global environmental sustainability also loom large. Research in hydrology and water resources management will be increasingly affected by (and increasingly important for) social development and conflict resolution at the international level. WRR remains committed to serving as a forum for dissemination of novel research that will address these themes. We look forward to the 
Acknowledgments

We dedicate this paper to all the former editors and deputy editors, current and former associate editors, conscientious reviewers, editorial assistants, and other AGU staff affiliated with WRR, who have contributed to WRR over the last 50 years. We also gratefully acknowledge the American Geophysical Union's support of WRR over the last 50 years. We contacted several former editors of WRR for clarifications on various aspects of its history. We thank them sincerely for sharing their insights and experience. Last but not least, we thank the entire hydrology community for their support-a journal succeeds only if it consistently receives excellent submissions from a community of authors. second 50 years of WRR, where continued research into physical, chemical, and biological processes and interactions between them, interactions between natural and anthropogenic systems, innovative measurement and sensing technologies, advanced modeling frameworks, and increasing collaborations between hydrology and other disciplines, will establish the foundations for an integrated understanding of water from local to global scales.

\section{References}

Blöschl, G., A. Bárdossy, D. Koutsoyiannis, Z. W. Kundzewicz, I. Littlewood, A. Montanari, and H. Savenije (2014), Joint Editorial: On the future of journal publications in hydrology, Water Resour. Res., 50, 2795-2797, doi:10.1002/2014WR015613.

Burges, S. J. (1984), Water Resources Research: The Twentieth Year, Water Resour. Res., 20(3), 321-322.

Burges, S. J. (1986), Trends and directions in hydrology, Water Resour. Res., 22(9), 1S-5S.

Burges, S. J. (1990), Water resources research: Past, present and future, Water Resour. Res., 26(7), 1321-1322.

Cohon, J. L. (1984), Taking stock and saying thank you, Water Resour. Res., 20(1), 1.

Davis, G. H. (1990), A quarter century of Water Resources Research, Water Resour. Res., 26(1) 2-4.

Freeze, R. A. (1981), A former editor views the editorial process, EOS Trans. AGU, 62(38), 673-675.

Freeze, R. A. (1990), Water resources research and interdisciplinary hydrology, Water Resour. Res., 26(9), 1865-1867.

Gray, W. G., and K. E. Bencala (2003), Editorial, Water Resour. Res., 39(11), 1325, doi:10.1029/2003WR002829.

Hornberger, G. M. (1993), Editorial, Water Resour. Res., 29(5) 1351-1352.

Kumar, P., T. Illangasekare, G. Sander, J. Selker, and T. Torgersen (2009), Editorial: Building on the legacy of Water Resources Research, Water Resour. Res., 45, W06101, doi:10.1029/2009WR008174.

Montanari, A., et al. (2013), "Panta Rhei-Everything Flows": Change in hydrology and society-The IAHS Scientific Decade 2013-2022, Hydrol. Sci. J., 58(6), 1256-1275.

Nash, J. E., P. S. Eagleson, J. R. Philip, W. H. Van der Molen, and V. Klemeš (1990), The education of hydrologists (Report of an IAHS/UNESCO Panel on hydrological education), Hydrol. Sci. J., 35(6), 597-607.

National Research Council (1991), Opportunities in the Hydrologic Sciences, Washington, D. C.

Parlange, M. B., B. Berkowitz, A. Porporato, T. Torgersen, and S. W. Tyler (2005), Editorial: Future of Water Resources Research, Water Resour. Res., 41, W01001, doi:10.1029/2004WR003899. 